Simultaneous Rough Rice Drying and Rice Bran Stabilization Using Infrared

\title{
Radiation Heating
}

\section{Tianxin Wang ${ }^{\mathrm{a}, \mathrm{b}}$, Ragab Khir ${ }^{\mathrm{a}, \mathrm{c}}$, Zhongli Pan ${ }^{\mathrm{a}, \mathrm{c}^{*}}$, Qipeng Yuan ${ }^{\mathrm{b}}$}

${ }^{a}$ Department of Biological and Agricultural Engineering, University of California, Davis, One Shields Avenue, Davis, CA 95616, USA

${ }^{\mathrm{b}}$ College of Life Science and Technology, Beijing University of Chemical Technology, Beijing, 100029, China

${ }^{\mathrm{d}}$ Department of Agricultural Engineering, Faculty of Agriculture, Suez Canal University, Ismailia, 41522, Egypt

${ }^{\mathrm{e}}$ Healthy Processed Foods Research Unit, USDA-ARS-WRRC, 800 Buchanan St., Albany, CA 94710, USA

Corresponding author. Zhongli Pan, Tel.: +1 510559 5861; fax: +1 5105595851.

E-mail address: zlpan@ucdavis.edu; zhongli.pan@ars.usda.gov 


\section{Abstract}

The objective of this study was to develop a new rice drying method using IR heating followed by tempering. Freshly harvested medium grain rice (M206) samples with different initial moisture contents (IMCs) were used in this study. The samples were dried for one- and two-passes using a catalytic IR emitter to reach rice surface temperature of $60{ }^{\circ} \mathrm{C}$. After IR heating, the samples were tempered in an incubator at $60{ }^{\circ} \mathrm{C}$ for different durations ranging from 1 to $5 \mathrm{~h}$. The effects of new drying method on moisture removal, milling quality, and shelf life of rice bran were evaluated. High heating and drying rates and good milling quality of rough rice were achieved. It took only $55 \mathrm{~s}$ to heat the rice samples to $60{ }^{\circ} \mathrm{C}$. For one-pass drying and $4 \mathrm{~h}$ tempering treatment, the total moisture removals were $3.33,3.78$ and $5.89 \mathrm{~g}$ moisture/100g dry solid for samples with initial moisture contents of 20.06, 25.53 and $32.50 \mathrm{~g}$ moisture/100g dry solid, respectively. IR heating did not generate adverse effects on milling quality of rough rice. Importantly, the storage stability of rice bran from the new drying method was extended to 38 days compared 7 days from current drying practice.

Keywords: Rough rice, Rice Bran, Drying, Infrared, Stabilization, Tempering, Milling quality. 


\section{Introduction}

Rice bran, an important by-product of rice milling, constitutes $8-10 \%$ of the weight of brown rice. It contains valuable components such as proteins, vitamins and essential minerals and has $15-22 \%$ of edible oil with high nutritional and functional characteristics (Luh, 1980). The antioxidants in the rice bran also showed effect in lowering cholesterol in humans (Carvalho, 2006). Despite of its high nutrition value rice bran is underutilized and frequently wasted, except it is used for producing oil. In general, utilization of rice bran is severely restricted by the activity of endogenous enzymes, such as lipase, which can hydrolyze the triglyceride into glycerol and free fatty acids (FFAs). When rice is milled, bran is scoured and lipase is exposed to the oxygen in air, then the oxidation starts, resulting in the deterioration of the oil quality and forming off flavor (Luh, 1980). It takes only less than one week to make the FFAs in the oil exceed $10 \%$, and then the rice bran oil is no longer suitable for human consumption (Desikachar, 1977; Qian et al., 2014). In order to better utilize the rice bran from rice milling process, the oil must be extracted quickly after milling process to control FFAs at a low level. However, this practice may not be feasible due to restriction of facility and production schedule (Randall, 1985). Therefore, it is a normal practice that the bran undergoes a stabilization process to inactivate the potent lipase enzyme immediately after milling to extend storage time at ambient conditions for controlling the FFAs concentration at a low level (less than 10\%) before oil extraction.

Many approaches on the stabilization of rice bran have been investigated and reported, 
such as chemical methods (Prabhakar and Venkatesh, 1986), heat methods (Rao Lakkakula et al., 2004), extrusion (Sayre et al., 1985) and microwave treatment (Tao et al., 1993). The most common method used in rice industry is extrusion even though it is an energy intensive process. The rice bran stabilization depends on temperature, duration of heat treatment, moisture content, $\mathrm{PH}$, and other parameters (Luh, 1980; Tao et al., 1993). Hot air heating could be used, but it may not be able to heat the bran quickly to the needed temperature with desired uniformity (Kim et al., 1987; Pacheco de Delahaye et al., 2005). The severe and non-uniform heating could damage valuable components and also result in high energy consumption. Moreover, these stabilization processes are typically operated right after rice milling, which may not be feasible for certain rice mills.

Freshly harvested rough rice is subjected to drying to reduce the MC to the safe storage level (14.9 g moisture/100g dry solid). At present, the hot air drying at a low air temperature (about $43^{\circ} \mathrm{C}$ or ambient air) is typically used in the rice industry to minimize the fissure of rice caused by high heat. The low drying temperature extends the required drying time and cannot inactivate the enzymes in the rice bran. Therefore, it is ideal to develop alternative techniques that can simultaneously achieve drying of rough rice and stabilization of rice bran.

Infrared (IR) radiation heating offers many advantages compared to conventional drying methods (Sharma et al., 2005 and Das et al., 2004). It may offer a promising potential in achieving efficient drying and simultaneously inactivating the lipase in rice bran without affecting the rice quality. When IR is used to heat or dry moist 
materials, the radiation impinges on the exposed material and penetrates it, and then the radiation energy is converted into heat (Ginzhurg, 2002). The penetration could provide more uniform heating in the rice kernel and may reduce the moisture gradient during heating and drying. Also, the rice can be quickly heated to high temperatures in a short time. Our previously consecutive studies have confirmed that high moisture diffusivity corresponding to high drying rate for rough rice can be achieved by using infrared (IR) heating to $60{ }^{\circ} \mathrm{C}$ followed by tempering treatment for $4 \mathrm{~h}$ and natural cooling. Simultaneously, effective disinfestation and disinfection have also been achieved without compromising milling quality. Extended shelf life of both rough and brown were also achieved (Pan et al., 2008 and 2011; Khir et al., 2011 and 2014, Wang et al., 2014; Ding et al. 2015 and 2016). Accordingly, drying using IR heating followed by tempering treatment may be an effective approach to achieve stabilized rice bran and extent its shelf life after milling without additional stabilization process. However, there is no literature published about the effects of IR heating and tempering treatment under one- and two-pass drying processes on drying characteristics, milling quality and shelf life of rice bran. Therefore, the objectives of this research were to (1) investigate the effects of IR heating and tempering treatment on the drying characteristics and milling quality of rough rice under one- and two-pass drying; (2) determine the effect of new drying method on the FFA concentration of rice bran oil over different storage periods; and (3) investigate the kinetics of lipase enzyme inactivation under IR heating and tempering treatments.

\section{Materials and methods}




\subsection{Samples}

Freshly harvested medium grain rice, variety M206, obtained from the Farmers' Rice Cooperative (West Sacramento, CA), was used for conducting this research. The initial moisture content (IMC) of rough rice at harvest was $32.51 \pm 0.09 \mathrm{~g}$ moisture/100g dry solid. In order to obtain rice samples with different (IMCs), the rice sample with the high MC was equally divided into three portions. Two portions were spread evenly on the floor in the thickness of $5 \mathrm{~cm}$ and slowly dried to $\mathrm{MC}$ of $25.54 \pm 0.11$ and $20.07 \pm 0.04 \mathrm{~g}$ moisture $/ 100 \mathrm{~g}$ dry solid under ambient conditions of temperature of $21 \pm 1^{\circ} \mathrm{C}$ and relative humidity ( $\left.\mathrm{RH}\right)$ of $42 \pm 3 \%$. During drying, the rice was mixed frequently to ensure to be uniformly dried. Finally, the rice samples with different IMCs of $20.07 \pm 0.04,25.54 \pm 0.11$ and $32.51 \pm 0.09 \mathrm{~g}$ moisture $/ 100 \mathrm{~g}$ dry solid were kept in polyethylene bags and sealed till they were used for IR drying and stabilization tests. All reported MCs are determined by the air oven method $\left(130^{\circ} \mathrm{C}\right.$, $24 \mathrm{~h}$ ) and reported on dry basis (d.b) (ASAE Standards, 1995).

\subsection{IR heating}

The rough rice samples with different IMCs were heated using IR device developed in the Food Processing Laboratory in the Department of Biological and Agricultural Engineering, University of California, Davis, California, USA. The detailed descriptions for IR unit were mentioned in our previous publications (Pan et al., 2008 and 2011; Khir et al., 2011 and 2014). The samples of a single layer with loading rate of $2 \mathrm{~kg} / \mathrm{m}^{2}$ were heated for one and two drying passes under radiation intensity of $5000 \mathrm{~W} / \mathrm{m}^{2}$. They were heated for $55 \mathrm{~s}$ to reach surface temperature of $60{ }^{\circ} \mathrm{C}$ during 
each drying pass. The temperature of $60{ }^{\circ} \mathrm{C}$ was determined based on previous findings (Pan et al., 2008 and 2011; Khir et al., 2011 and 2014) that indicted that the high drying rate corresponding to good milling quality could be achieved by heating rough rice to aforementioned temperature level using IR. The temperature was measured by a Type $\mathrm{T}$ thermocouple (Omega Engineering Inc. Stamford, CT) immediately after samples were heated. The thermocouple was kept at the center of rough rice in a container until the temperature reading was stabilized, which took from 10 to 30s. The rice sample masses were measured by a balance with two-decimal accuracy before and after IR heating. The mass loss during heating and IMC were used to calculate the moisture removal during the IR heating durations. The moisture loss was calculated as the difference between the IMC and the MC after IR heating and is reported as g moisture/100g dry solid.

\subsection{Tempering and cooling treatments}

After IR heating, the tempering and cooling treatments were conducted. The tempering treatment was conducted by keeping the samples in closed container placed in an incubator set at $60{ }^{\circ} \mathrm{C}$ for various durations (1, 2, 3, 4 and 5h). After tempering treatment, the samples were cooled under ambient conditions at temperature of $21 \pm 1^{\circ} \mathrm{C}$ and $\mathrm{RH}$ of $42 \pm 3 \%$. They reached to the ambient temperature after $1 \mathrm{~h}$. Then after tempering and cooling treatments the samples were further dried to MC of 14.94 g moisture/100g dry solid using the ambient air.

For the two-pass drying, after infrared heating followed by tempering and cooling treatment as the first pass, the rough rice with initial high $\mathrm{MC}$ was left in the room 
temperature overnight. The samples were heated using IR to the surface temperature to $60{ }^{\circ} \mathrm{C}$ again, and then followed by tempering for different durations ranging from $0-5 \mathrm{~h}$. The mass changes caused by tempering and cooling treatment were recorded at the end of cooling and used to calculate the moisture loss based on the MCs after the corresponding IR treatment.

\subsection{Evaluation of milling quality}

The indicators of rice milling quality including, total rice yield (TRY), head rice yield (HRY) and whiteness index (WI) were evaluated. The treated and untreated rice samples were dehulled and milled using a Yamamoto Husker (FC-2K) and Yamamto Rice Mill (VP-222N, Yamamoto Co. Ltd., Japan). The samples were milled three times to achieve well-milled rice as defined by the Federal Grain Inspection Service (USDA, 1994). The setting of throughput and whitening were 1 and 4, respectively, during the first two milling passes and 1 and 5 during the third milling pass.

TRY, HRY and WI were used to evaluate the effects of IR heating and tempering treatments on milling quality. The HRY was determined with Graincheck (Foss North America, Eden Prairie, MN). The WI was determined by the whiteness tester (C-300, Kett Electronic Laboratory, Tokyo, Japan). A higher index number indicates whiter milled rice. All reported milling quality indicators are averages of three replicates.

\subsection{Measurement of FFAs concentration}

The FFA concentration of oil from rice bran obtained by milling the rough rice samples were determined and compared to those of untreated samples (control). The treated and untreated rice bran samples were packed in plastic ziplock bags and stored 
for 38 days at temperature of $20 \pm 1{ }^{\circ} \mathrm{C}$ and $\mathrm{RH}$ of $46 \pm 3 \%$. To measure FFA concentration, rice bran samples of $2 \mathrm{~g}$ was mixed with $40 \mathrm{~mL}$ hexane and shaken for $1 \mathrm{~h}$ at $20^{\circ} \mathrm{C}$ at $3 \times \mathrm{g}$. The mixture was then centrifuged for $6 \mathrm{~min}$ at $1192 \times \mathrm{g}$ using centrifugation (Eppendorf 5810 R, Germany). The amount of extracted oil was then measured gravimetrically. The concentration of total FFAs in rice bran oil (RBO), which expressed as oleic acid percentage, was evaluated according to alcoholic alkali titration method. After extraction and evaporation of hexane, $3 \mathrm{~cm}^{3}$ ethanol with $5 \mathrm{~g} / \mathrm{L}$ phenolphthalein was added to the extracted oil. The mixture was stirred sufficiently and then titrated by $20 \mathrm{~mol} / \mathrm{L}$ aqueous $\mathrm{NaOH}$. During the titration, the mixture was vigorously shaken until the first permanent pink color appeared (Pourali et al., 2009). The total FFAs percentage was calculated using equation (1).

$$
F F A \%=\frac{V_{\mathrm{NaOH}} \cdot N_{\mathrm{NaOH}} \cdot 282.5}{10 \cdot m_{\text {oil }}} \times 100 \%
$$

where FFA\% was FFA percentage in $\mathrm{RBO}$ (g/ $100 \mathrm{~g}$ RBO), $\mathrm{V}_{\mathrm{NaOH}}$ was amount of titrant $\left(\mathrm{cm}^{3}\right), \mathrm{N}_{\mathrm{NaOH}}$ was normality of titrant $\left(\mathrm{mmol} / \mathrm{cm}^{3}\right), 282.5$ was oleic acid molecular weight and $\mathrm{m}_{\text {oil }}$ was $\mathrm{RBO}$ weight $(\mathrm{g})$. All the procedures mentioned above are illustrated in Figure 1.

\subsection{Kinetics of lipase-catalyzed reaction}

The lipase-catalyzed reaction was determined by formation of FFAs in RBO. The lipase reaction kinetic was described by the following model: (Levenspiel, 1999; Pourali et al., 2009) and equation (2) was applied.

Triglycerides $\frac{\text { Lipase }}{k\left(k_{1}, k_{2}\right)}$ FFAs 


$$
r_{F F A}=\frac{d C}{d t}=\frac{k_{1} C}{k_{2} C-1}
$$

where $C$ is total FFAs concentration (g/100g RBO), $t$ is storage time (day), and $k_{1}\left(\right.$ day $\left.^{-1}\right)$ and $k_{2}(100 \mathrm{~g}$ RBO/g FFAs) are kinetic parameters of FFAs formation. Integration of equation (2) under the initial condition of $C=C_{0}$ at $t=0$ gives the following equation (3):

$\frac{\ln (A+1)}{t}=\frac{k_{2} C_{0} A}{t}-k_{1}$

where $A$ is defined as equation (4):

$A=\frac{C-C_{0}}{C_{0}}$

By plotting of $(\ln (A+1)) t^{-1}$ versus $A t^{-1}$, kinetic parameters $\left(k_{1}\right.$ and $\left.k_{2}\right)$ can be determined for the FFAs formation reaction in the stored rice bran under temperature of $20 \pm 1^{\circ} \mathrm{C}$.

\subsection{Statistical analysis}

The obtained data were statistically analyzed using PASS software (IBM Chicago, IL). The significant differences at $(\mathrm{P}<0.05)$ of the $\mathrm{t}$-test with the assumption of equal variances was applied to compare milling quality indicators, including, TRY, HRY and WI under the tested conditions. In addition, multiple comparisons were applied to compare FFA concentrations for significant differences at $\mathrm{P}<0.05$.

\section{Results and discussion}

\subsection{Moisture removal under IR heating and tempering treatment}

As expected, high heating and moisture removal were achieved using IR heating. It took only 55 s to heat rough rice to surface temperature of $60{ }^{\circ} \mathrm{C}$ with corresponding 
moisture removal of $1.75,2.19$ and $2.91 \mathrm{~g}$ moisture/100g dry solid for the rice samples with IMCs of 20.06, 25.53 and $32.50 \mathrm{~g}$ moisture/100g dry solid, respectively, as shown in Figure $2(\mathrm{a}, \mathrm{b}$ and $\mathrm{c})$. After IR heating, the tempering treatment significantly improved the moisture removal during natural cooling. For one-pass drying, the moisture removal during natural cooling increased with the increase of tempering time. The moisture removal after natural cooling increased from 0.81, 1. 50 and $2.20 \mathrm{~g}$ moisture/100g dry solid to $1.50,1.40$ and $2.60 \mathrm{~g}$ moisture/100g dry solid by increasing tempering time from $1 \mathrm{~h}$ to $4 \mathrm{~h}$ for the samples with IMCs of 20.06, 25.53 and $32.50 \mathrm{~g}$ moisture/100g dry solid, respectively. The corresponding total moisture removals were 2.56, 3.70, $5.10 \mathrm{~g}$ moisture/100g dry solid, and 3.33, 3.78, $5.89 \mathrm{~g}$ moisture $/ 100 \mathrm{~g}$ dry solid. It is important to notice that a considerable moisture removal was achieved by conducting tempering treatment and natural cooling without any energy consumption. After $4 \mathrm{~h}$ of tempering, about $49.87 \%, 38.88 \%$, and $47.27 \%$ of total moisture removal were achieved during natural cooling of the samples with IMCs of 20.06, 25.53 and $32.50 \mathrm{~g}$ moisture/100g dry solid, respectively. While the total moisture removal reached to $12.27 \mathrm{~g}$ moisture/100g dry solid, under two-pass drying and tempering treatment of more than $3 \mathrm{~h}$ for samples with IMCs of $32.5 \mathrm{~g}$ moisture/100g dry solid as shown in Fig. 3. Thus, the tempering process reduced the moisture gradient in rice kernels and allowed the moisture to equilibrate before the rice kernels were cooled. Therefore, the tempering process is a critical step to increase the moisture removal during cooling of the rough rice. These results are in agreement with those we reported before (Pan et al., 2008; Khir et al., 2011; Ding et al. 2015). 
This confirms that IR heating followed by tempering and natural cooling could achieve high heating and high drying efficiency for rough rice.

\subsection{Milling quality}

Milling quality indicators, including TRY, HRY, and WI under different IR and tempering treatments for rough rice samples with different IMCs are shown in Tables 1 and 2. In general, IR heating followed by tempering treatment led to improve TRY and HRY for samples with different IMCs compared to the controls. For example, the average of TRYs for rough rice heated using IR to $60{ }^{\circ} \mathrm{C}$ followed by tempering treatment for $4 \mathrm{~h}$ were $66.59 \%, 67.63 \%$ and $66.03 \%$ which were $3.77 \%, 5.06 \%$ and $1.02 \%$ significantly higher those of the controls for samples with IMCs of 25.53, $32.50 \mathrm{~g}$ moisture/100g dry solid under one-pass drying and $32.50 \mathrm{~g}$ moisture/100g dry solid two-pass drying, respectively. The corresponding HRYs were 51.61\%, and $49.80 \%, 50.89 \%$. The TRY and HRY of samples with low MC of $20.06 \mathrm{~g}$ moisture/100g dry solid were slightly lower than those of controls. However, there is no significant difference between the tested samples and the controls.

When the color results of milled rice were examined, it was observed that the WI of the treated samples was less than that of the control. This may be due to storing rice for a long time before conducting the experiments. During the storage, color leaching from the hull and bran layer into the endosperm layer of rice might accoured. This is similar to what we have observed before, which could be caused by the less degree of milling (Ding et al. 2015 and 2016).

Based on the milling quality results, it can be seen that using IR heating followed by 
tempering treatments to dry rough rice led to achieve high moisture removal corresponding to good rice milling quality. The reason why the high temperature of IR heating did not damage the milled rice quality could be due to the relatively uniform heating in the rice kernel resulting in a lower moisture gradient compared to conventional hot air drying. Additionally, the results indicated that the rice milling quality may not be compromised with a relatively large amount of moisture removal in a single drying pass with a high drying rate if the rice can be heated quickly and uniformly, minimizing the moisture gradient. When a large amount of moisture is removed during IR heating, tempering is very important to re-establish the moisture equilibrium in the rice kernels. Moreover, it is important to notice that by applying two-pass dying approach, high moisture removal could be achieved without compromising the rough rice quality.

\subsection{Effectiveness of enzyme inactivation}

To evaluate the effectiveness of IR heating on inactivation of lipase enzyme, the FFA concentrations were determined for rice bran samples produced from milling of rough rice samples with different initial MCs treated with IR followed by tempering treatments and stored for different durations (Fig 4). It can be seen that the concentration of FFAs increased in the course of storage time under all tested conditions. However, concentration profiles of treated samples and the control are different. For untreated samples (control), the FFA concentration increased sharply to more than $10 \%$ during less than seven days of storage. This means that FFAs formed as a result of hydrolysis reaction in the rice bran and lipase enzyme catalyzed this 
reaction to proceed rapidly. Thus untreated rice bran cannot be utilized for edible oil production after one week from the date of rice milling based on industrial practice. The FFA results from air dried rice are in agreement with those reported by Pourali et al. (2009). This confirms the necessity to inactivate the lipase enzyme that responsible for rice bran degradation and instability.

For samples treated with IR followed by tempering treatment for more than three hours, the FFA concentration increased gradually to $10 \%$ after 17, 19 and 30 days of storage for samples with initial MC of 20.06, 25.53 and $32.5 \mathrm{~g}$ moisture/100g dry solid (Fig 4 a, b and c). Moreover, for two-pass treatment, the FFA concentration reached $10 \%$ after 38 days for rough rice samples with initial MC of $32.5 \mathrm{~g}$ moisture/100g dry solid treated with IR followed by tempering treatment for 4 hours during each drying pass (Fig. 5). This means that the IR heating followed by tempering treatments has a destructive effect on lipase activity. The lipase activity declined with increase of tempering time and initial moisture content of the rough rice. Thus tempering treatment is one of essential part of the new drying process to inactivate the enzyme and extend the storage satiability of rice bran. The integrated IR drying and tempering treatment, particularly for high initial moisture rice, created an effective moist heat-treatment for lipase inactivation. It has been reported that the heat resistance of lipase depends on temperature, treatment time, and moisture content. The moisture content is a critical parameter. The higher the moisture content, the lower the heat resistance of lipase (Luh, 1980; Randall, 1985). Additionally, our previous study (Wang el al., 2014) has revealed that an increase in moisture content of 
rough rice improved disinfection effect of IR heating followed by tempering treatment. High moisture of rough rice created a wet and warm environment during tempering treatment and effectively denature the portion of A. flavus spores. Since the lipase enzyme is protein, a similar effect could take place.

It is important to notice that the rough rice is typically harvested at moisture content ranging from 25.0 to $32.0 \mathrm{~g}$ moisture/100g dry solid (Mutters and Thompson, 2006). This means the heating of freshly harvested rough rice to $60{ }^{\circ} \mathrm{C}$ using IR followed by tempering treatment for three hours or longer can be an effective approach to inactivate the lipase and extend the storage stability of rice bran for up to 38 days after milling. At the same time, high drying rate and good milling quality can be simultaneously achieved for rough rice. These results are in agreement with those we reported before (Pan et al., 2008 and 2011; Khir et al., 2011 and 2014, Wang et al., 2014; Ding et al. 2015 and 2016). These findings indicate the promising potential of this technology to be applied in the commercial scale in the rice industry.

\subsection{Kinetics of FFAs formation}

The formation of FFAs plays an important role to create deteriorative changes and affect the quality of RBO. Consequently, application of an accurate kinetic model to understand and predict the FFAs formation could be a useful to determine RBO rancidity rate and feasibility of full utilization of rice bran. To further describe the effect of IR heating and tempering treatments on the inactivation of lipase in rice bran and estimate the storage time which FFAs concentration is kept below 10\%, the kinetic of FFAs formation was investigated for the one- and two-pass dryings for rice 
samples with different IMCs. The kinetics of FFAs formation were determined by regression relationships of kinetic data. The slope determined by the $\mathrm{k}_{2}$ and $\mathrm{k}_{1}$ values was represented by intercept. Based on the $\mathrm{k}_{1}$ and $\mathrm{k}_{2}$, the storage time required to reach to $10 \%$ of FAA was estimated.

In Table 3, it can be seen that there is a good agreement between the experimental and kinetics data according to the high $\mathrm{R}^{2}$ value for treated and control samples under oneand two-pass dryings. The values of $k_{1}$ and $k_{2}$ of controls were significantly higher than those of treated samples. When the tempering time increased, the $k_{1}$ and $k_{2}$ values decreased, which suggested that the lipase activity was reduced. For example, by increasing the tempering time for $1 \mathrm{~h}$ to $5 \mathrm{~h}$, the $\mathrm{k}_{1}$ and $\mathrm{k}_{2}$ values of samples with IMC of $25.54 \mathrm{~g}$ moisture/100g dry solid decreased form 0.2022 day $^{-1}$ and $0.5412(100 \mathrm{~g}$ RBO/g FFAs) to 0.0834 day $^{-1}$ and 0.4736 (100 g RBO/g FFAs) for the one-pas drying samples. Moreover, with increasing in initial moisture content, the lipase activity reduced further under one- and two-pass dryings. At $4 \mathrm{~h}$ of tempering time, the $\mathrm{k}_{1}$ and $\mathrm{k}_{2}$ values decreased from $0.149 \mathrm{day}^{-1}$ and 0.511 (100 g RBO/g FFAs) of rice samples with IMC of $20.02 \mathrm{~g}$ moisture/100g dry solid to 0.036 day $^{-1}$ and 0.3680 (100 g RBO/g FFAs) for samples with IMC of $32.54 \mathrm{~g}$ moisture/100g dry solid. The corresponding values under two-pass drying were 0.023 day $^{-1}$ and 0.357 (100 g RBO/g FFAs). According to the $k_{1}$ and $k_{2}$ obtained from the regression, the storage time during which FFA concentration kept under $10 \%$ was estimated, which exhibited the similar trend as those of the experimental results. The obtained results showed that the simplified kinetics model can successfully describe and predict the FFAs formation in the course 
of rice bran storage. The model can be used by food industries to prepare an accurate manufacturing plan for processing rice bran into edible oil prior to its deterioration.

\section{Conclusion}

The research showed that high heating rate, drying efficiency and milling quality for rough rice can be achieved by using infrared heating followed by tempering treatment and natural cooling under one- and two-pass drying processes. It took only $55 \mathrm{~s}$ to heat rough rice to surface temperature of $60^{\circ} \mathrm{C}$. The total moisture removals during IR heating for one-pass drying followed by tempering treatment for $4 \mathrm{~h}$ and natural cooling were 3.33, 3.78 and $5.89 \mathrm{~g}$ moisture/100g dry solid for samples with IMCs of 20.06, 25.53 and $32.50 \mathrm{~g}$ moisture/100g dry solid, respectively. The corresponding total moisture removal reached to $12.27 \mathrm{~g}$ moisture/100g dry solid for samples with IMCs of $32.5 \mathrm{~g}$ moisture/100g dry solid treated for two-pass drying. TRY and HRY values for rough rice with high initial moisture were higher than those of the control. However, WI values were slightly less than that of the control. Importantly, the IR heating and tempering treatments showed a promising potential to achieve an effective stabilization for rice bran during storage after milling. The IR heating of rough rice to $60{ }^{\circ} \mathrm{C}$ followed by tempering treatment for 4 or $5 \mathrm{~h}$ resulted in significant reduction in lipase activity, particularly for rice with high initial MC. Consequently, the storage time of stabilized rice bran with FFA concentration less than $10 \%$ could be extend to 38 days under two-pass drying compared to 7 days for the control. The results indicate that IR heating can achieve simultaneous drying and effective stabilization for rice bran and provide a more effective way for the 
utilization of rice bran without affecting the quality of rice bran oil.

\section{Acknowledgements}

The experiments and the data analysis of this research work were conducted and completed in the Department of Biological and Agricultural Engineering, University of California, Davis and Western Regional Research Center, USDA-ARS. The authors thank Farmers' Rice Cooperative for supplying the fresh rice samples and the California Rice Research Board for partial financial support.

Abbreviations

IMC initial moisture content, g moisture/100g dry solid,

IR Infrared radiation,

FFA Free fatty acid,

HRY Head rice yield,

MC Moisture content, g moisture/100g dry solid,

RBO Rice bran oil,

TRY Total rice yield,

WI Whiteness index

\section{References}

ASAE Standards (1995). S352.2: 1 Moisture measurements-Unground grain seeds Moisture relationships of grains (42nd ed.). St. Joseph, MI: ASAE.

Carvalho, F. P. (2006). Agriculture, pesticides, food security and food safety. Environmental Science \& Policy, 9 (7-8), 685-692. 
Das, I., Das, S. K., \& Bal, S. (2004). Drying performance of a batch type vibration aided infrared dryer. Journal of Food Engineering, 64, 129-133.

Desikachar, H. S. R. (1977). Preservation of byproducts of rice milling. Proceeding of the Rice By-Products Utilization, Valencia, Spain.

Ding, C., Khir, R., Pan, Z., Zhao, L., Tu, K., El-Mashad, H., \& McHugh, T. H. (2015). Improvement in Shelf Life of Rough and Brown Rice Using Infrared Radiation Heating. Food Bioprocess Technol., 8(5), 1149-1159.

Ding, C., Khir, R., Pan, Z.,Wood, d. F., Tu, K., El-Mashad, H., \& Berrios, J. (2016). Improvement in Storage Stability of Infrared-Dried Rough Rice. Food Bioprocess Technol., DOI 10.1007/s11947-016-1690-5 (9), 1010-1020.

Ginzburg, A.S. (2002). Infrared heating; Infrared drying equipment. Leonard Hill Books, London.

Khir, R., Pan, Z., Thompson J. F., El-Sayed A. S., Hartsough B. R., \& El-Amir M. S. (2014). Moisture removal characteristics of thin layer rough rice under sequenced infrared radiation heating and cooling. Journal of Food Processing and Preservation, 38 (1), 430-440.

Khir, R., Pan, Z., Salim, Adel., Hartsough, B. R., \& Mohamed, S. (2011). Moisture diffusivity of rough rice under infrared radiation drying. LWT- Food Science and Technology, 44 (4), 1126-1132.

Kim, C.J., Byun, S. M., Cheigh, H. S., \& Kwon, T. W. (1987). Comparison of solvent extraction characteristics of rice bran pretreated by hot air drying, steam cooking and extrusion. Journal of the American Oil Chemists' Society, 64(4), 514-516. 
Levenspiel, O. (1999). Chemical Reaction Engineering. (Third ed.) John Wiley \& Sons, USA.

Luh, B. S. (1980). Rice: Production and utilization. AVI Publishing Company, INC. Westport, Connecticut.

Mutters, R. G. \& Thompson, J. F. (2009). Rice Quality Handbook. Publication 3514. Oakland, Cal. University of California, Department of Agricultural and Natural Resources.

Pacheco de Delahaye, E., Jimenez, Paula., \& Perez, E., (2005). Effect of enrichment with high content dietary fiber stabilized rice bran flour on chemical and functional properties of storage frozen pizzas. Journal of Food Engineering, 8 (1), $1-7$.

Pan, Z., Khir, R., Bett-Garber, K.L., Champagne, E.T., Thompson, J. F., Salim, A., Hartsough, B.R., \& Mohamed, S. (2011). Drying characteristics and quality of rough rice under infrared radiation heating. Transactions of the ASABE, 54 (1), 203-210

Pan, Z., Khir, R., Godfrey, L. D., Lewis, R., Thompson, J. F., \& Salim, A. (2008). Feasibility of simultaneous rough rice drying and disinfestations by infrared radiation heating and rice milling quality. Journal of Food Engineering, 84 (3), 469-479.

Pourali, O., Asghari, F. S., \& Yoshida, H. (2009). Simultaneous rice bran oil stabilization and extraction using sub-critical water medium. Journal of Food Engineering, 95 (3), 510-516. 
Prabhakar, J.V., \& Venkatesh, K. V. L. (1986). A simple chemical method for stabilization of rice bran. Chemistry and Materials Science, 63 (5), 644-646.

Qian, J. Y, Gu, Y.P., Jiang, W., \& Chen, W. (2014). Inactivating effect of pulsed electric field on lipase in brown rice. Innovative Food Science and Emerging Technologies, 22, 89-94.

Randall, J.M., Sayre, R.N., Schultz, W. G., Fong, R. Y., Mossman, A. P., Tribelhorn, R. E., \& Saunders, R.M. (1985). Rice bran stabilization by extrusion cooking for extraction of edible oil. Journal of Food Science, 50, 361-364.

Rao Lakkakula, N., Lima, M., \& Walker, T. (2004). Rice bran stabilization and rice bran oil extraction using ohmic heating. Bioresouce Technology, 92 (2), 157-161.

Sayre, R. N., Nayyar, D. K., \& Saunders, R. M. (1985). Extraction and refining of edible oil from extrusion-stabilized rice bran. Journal of the American Oil Chemists'Society, 62 (6), 1040-1043.

Sharma, G. P., Verma, R. C., \& Pathare, P. B. (2005). Thin-layer infrared radiation drying of onion slices. Journal of Food Engineering, 67, 361-366.

Tao, J., Rao, R., \& Liuzzo, J. (1993). Microwave heating for rice bran stabilization. Journal of Microwave Power and Electromagnetic Energy, 38 (3), 156-164.

USDA Federal Grain Inspection Service, (1994). Rice Inspection Handbook. Agricultural Marketing Service. Washington D.C.

Wang, B., Khir, R., Pan, Z., El-Mashad, H., Atungulu, G. G., \& Ma, H. (2014). Effective disinfection of rough rice using infrared radiation heating. Journal of Food Protection, 77(9): 1538-1545. 
Table 1. Total rice yield (TRY) and head rice yield (HRY) of rough rice with initial different IMCs under IR heating and tempering treatment for different durations.

\begin{tabular}{|c|c|c|c|c|c|c|c|c|}
\hline \multirow{3}{*}{$\begin{array}{l}\text { IR heating and } \\
\text { tempering duration }\end{array}$} & \multicolumn{8}{|c|}{ Initial moisture content $\left(\mathrm{g} 100 \mathrm{~g}^{-1}\right)$} \\
\hline & \multicolumn{2}{|c|}{20.06 (One pass) } & \multicolumn{2}{|c|}{25.53 (One pass) } & \multicolumn{2}{|c|}{32.50 (One pass) } & \multicolumn{2}{|c|}{32.50 (Two passes) } \\
\hline & TRY & HRY & TRY & HRY & TRY & HRY & TRY & HRY \\
\hline Control & $64.23 \pm 0.27 \mathrm{a}$ & $49.84 \pm 1.47 \mathrm{a}$ & $62.82 \pm 0.16 a$ & $50.01 \pm 1.34 \mathrm{a}$ & $62.57 \pm 0.40 \mathrm{a}$ & $49.3 \pm 1.24 \mathrm{a}$ & $65.01 \pm 0.07 \mathrm{a}$ & $49.38 \pm 0.47 \mathrm{a}$ \\
\hline IR & $63.10 \pm 0.28 \mathrm{a}$ & $48.02 \pm 0.96 \mathrm{a}$ & $66.89 \pm 0.72 c$ & $50.87 \pm 1.21 \mathrm{a}$ & $66.20 \pm 1.37 \mathrm{~b}$ & $49.67 \pm 2.24 \mathrm{a}$ & $66.33 \pm 0.62 b$ & $48.98 \pm 2.16 \mathrm{a}$ \\
\hline $1 \mathrm{~h}$ & $63.28 \pm 0.31 \mathrm{a}$ & $48.04 \pm 1.43 \mathrm{a}$ & $65.92 \pm 0.88 \mathrm{c}$ & $50.84 \pm 1.01 \mathrm{a}$ & $67.00 \pm 1.00 \mathrm{~b}$ & $49.50 \pm 1.20 \mathrm{a}$ & $66.65 \pm 0.43 b$ & $50.30 \pm 0.75 \mathrm{a}$ \\
\hline $2 \mathrm{~h}$ & $63.08 \pm 0.22 \mathrm{a}$ & $48.13 \pm 2.39 a$ & $66.64 \pm 0.93 c$ & $52.00 \pm 1.56 \mathrm{~b}$ & $67.36 \pm 0.27 b$ & $49.29 \pm 1.36 \mathrm{a}$ & $65.81 \pm 0.51 \mathrm{ab}$ & $49.99 \pm 0.70 \mathrm{a}$ \\
\hline $3 \mathrm{~h}$ & $62.30 \pm 1.00 \mathrm{~b}$ & $47.60 \pm 1.09 \mathrm{a}$ & $66.63 \pm 0.46 c$ & $51.41 \pm 0.73 b$ & $66.81 \pm 1.27 \mathrm{~b}$ & $49.81 \pm 2.46 \mathrm{a}$ & $66.25 \pm 0.31 b$ & $51.39 \pm 0.81 \mathrm{a}$ \\
\hline $4 \mathrm{~h}$ & $62.15 \pm 0.54 b$ & $47.99 \pm 2.41 \mathrm{a}$ & $66.59 \pm 1.23 \mathrm{c}$ & $51.61 \pm 0.62 b$ & $67.63 \pm 0.07 b$ & $49.80 \pm 0.83 a$ & $66.03 \pm 0.07 b$ & $50.89 \pm 0.54 \mathrm{a}$ \\
\hline $5 \mathrm{~h}$ & $63.53 \pm 0.75 a$ & $48.11 \pm 1.43 \mathrm{a}$ & $66.74 \pm 0.53 c$ & $51.54 \pm 0.25 b$ & $68.14 \pm 0.91 b$ & $49.02 \pm 0.59 \mathrm{a}$ & $65.85 \pm 0.66 a b$ & $50.65 \pm 2.92 \mathrm{a}$ \\
\hline
\end{tabular}

Values (means \pm standard deviation) in each column with different letters are significantly different at $\mathrm{p}<0.05$. 
Table 2. Whiteness index (WI) of rough rice with initial different IMCs under IR heating and tempering treatment for different durations.

\begin{tabular}{|c|c|c|c|c|}
\hline \multirow{3}{*}{$\begin{array}{l}\text { Infrared and } \\
\text { tempering } \\
\text { treatments }\end{array}$} & \multicolumn{4}{|c|}{ Initial moisture content $\left({\left.\mathrm{g} 100 \mathrm{~g}^{-1}\right)}^{-1}\right.$} \\
\hline & \multicolumn{3}{|c|}{ One pass } & \multirow{2}{*}{$\begin{array}{c}\text { Two passes } \\
32.50\end{array}$} \\
\hline & 20.06 & 25.53 & 32.50 & \\
\hline Control & $41.03 \pm 0.25 \mathrm{a}$ & $38.93 \pm 1.00 \mathrm{a}$ & $40.67 \pm 0.80 \mathrm{a}$ & $25.63 \pm 3.01 \mathrm{a}$ \\
\hline IR & $40.53 \pm 1.27 \mathrm{a}$ & $35.10 \pm 0.82 b$ & $33.33 \pm 1.43 b$ & $28.33 \pm 0.40 b$ \\
\hline $1 \mathrm{~h}$ & $41.47 \pm 0.32 \mathrm{a}$ & $35.00 \pm 2.40 \mathrm{~b}$ & $32.10 \pm 1.21 b$ & $29.10 \pm 0.65 b$ \\
\hline $2 \mathrm{~h}$ & $40.10 \pm 0.44 a$ & $33.30 \pm 1.25 b$ & $31.03 \pm 0.72 b$ & $30.05 \pm 3.36 b$ \\
\hline $3 h$ & $40.80 \pm 2.46 \mathrm{a}$ & $32.23 \pm 1.46 b c$ & $31.27 \pm 1.05 b$ & $25.63 \pm 3.0 \mathrm{a} 1$ \\
\hline $4 \mathrm{~h}$ & $40.20 \pm 1.51 \mathrm{a}$ & $33.46 \pm 0.68 b$ & $30.8 \pm 1.39 b c$ & $28.33 \pm 0.40 b$ \\
\hline $5 \mathrm{~h}$ & $39.83 \pm 2.03 \mathrm{a}$ & $33.23 \pm 0.97 b$ & $29.27 \pm 0.84 b c$ & $29.10 \pm 0.65 b$ \\
\hline
\end{tabular}

Values (means \pm standard deviation) in each column with different letters are significantly different at $\mathrm{p}<0.05$. 
Table 3 Kinetics parameters and estimated storage time for single and multiples IR/tempering treatments for different moisture contents

Drying

Initial MC

pass

$\left({\left.\mathrm{g} 100 \mathrm{~g}^{-1}\right)}\right.$ Parameters Control IR

Tempering duration (h)

\begin{tabular}{|c|c|c|c|c|c|c|c|c|}
\hline$\delta 100$ ह & & & & 1 & 2 & 3 & 4 & 5 \\
\hline & $\mathrm{R}^{2}$ & 0.9949 & 0.8365 & 0.8363 & 0.8813 & 0.8830 & 0.8782 & 0.8781 \\
\hline 20.05 & $\mathrm{k}_{1}$ & 0.1354 & 0.2272 & 0.1096 & 0.0484 & 0.1571 & 0.1490 & 0.2417 \\
\hline & $\mathrm{k}_{2}$ & 0.3144 & 0.4776 & 0.3558 & 0.2864 & 0.5240 & 0.5110 & 0.6651 \\
\hline Estimate & ge (day) & 6.9 & 9.3 & 10.4 & 12.2 & 16.8 & 17.1 & 18.2 \\
\hline & $\mathrm{R}^{2}$ & 0.9338 & 0.9312 & 0.9492 & 0.9060 & 0.9130 & 0.8510 & 0.8132 \\
\hline 25.54 & $\mathrm{k}_{1}$ & 0.2600 & 0.1871 & 0.2022 & 0.1439 & 0.1843 & 0.1300 & 0.0834 \\
\hline & $\mathrm{k}_{2}$ & 0.5080 & 0.4525 & 0.5412 & 0.4823 & 0.5630 & 0.5080 & 0.4736 \\
\hline Estimate & se (day) & 9.2 & 9.5 & 12.6 & 14.1 & 19.3 & 20.7 & 23.4 \\
\hline & $\mathrm{R}^{2}$ & 0.8570 & 0.8523 & 0.8979 & 0.7667 & 0.9245 & 0.9450 & 0.9962 \\
\hline 32.54 & $\mathrm{k}_{1}$ & 0.3829 & 0.4329 & 0.4080 & 0.0979 & 0.1579 & 0.0360 & 0.0358 \\
\hline & $\mathrm{k}_{2}$ & 0.5930 & 0.7151 & 0.8055 & 0.3599 & 0.5228 & 0.3680 & 0.3844 \\
\hline Estimate & se (day) & 7.7 & 8.8 & 12.13 & 13.4 & 29.6 & 38.2 & 41.5 \\
\hline & $\mathrm{R}^{2}$ & 0.9456 & 0.9002 & 0.6942 & 0.6942 & 0.7272 & 0.8150 & 0.9811 \\
\hline 32.54 & $\mathrm{k}_{1}$ & 0.3324 & 0.0441 & 0.0583 & 0.0122 & 0.0289 & 0.0230 & 0.0115 \\
\hline & $\mathrm{k}_{2}$ & 0.5611 & 0.3244 & 0.4805 & 0.3104 & 0.3693 & 0.3570 & 0.2458 \\
\hline Estimate & se (day) & 8.2 & 24.0 & 31.5 & 37.7 & 39.7 & 45.4 & 48.0 \\
\hline
\end{tabular}


Figure Captions

Figure 1. The procedures of IR heating, tempering treatment, and evaluation milling quality and FFA concentration.

Figure 2. Moisture loss under infrared heating and tempering treatments for rough rice with IMC of (A) 20.06; (B) 25.45; (C) 32.45 and (D) $32.45 \mathrm{~g}$ moisture/100g dry solid for two-pass drying

Figure 3. Total FFAs concentration (as oleic acid percentage in RBO) in treated rice bran produced from treated rough rice with IMCs of (A)20.06, (B) 25.45,(C) 32.45 and (D) $32.45 \mathrm{~g}$ moisture/100g dry solid for two-pass drying

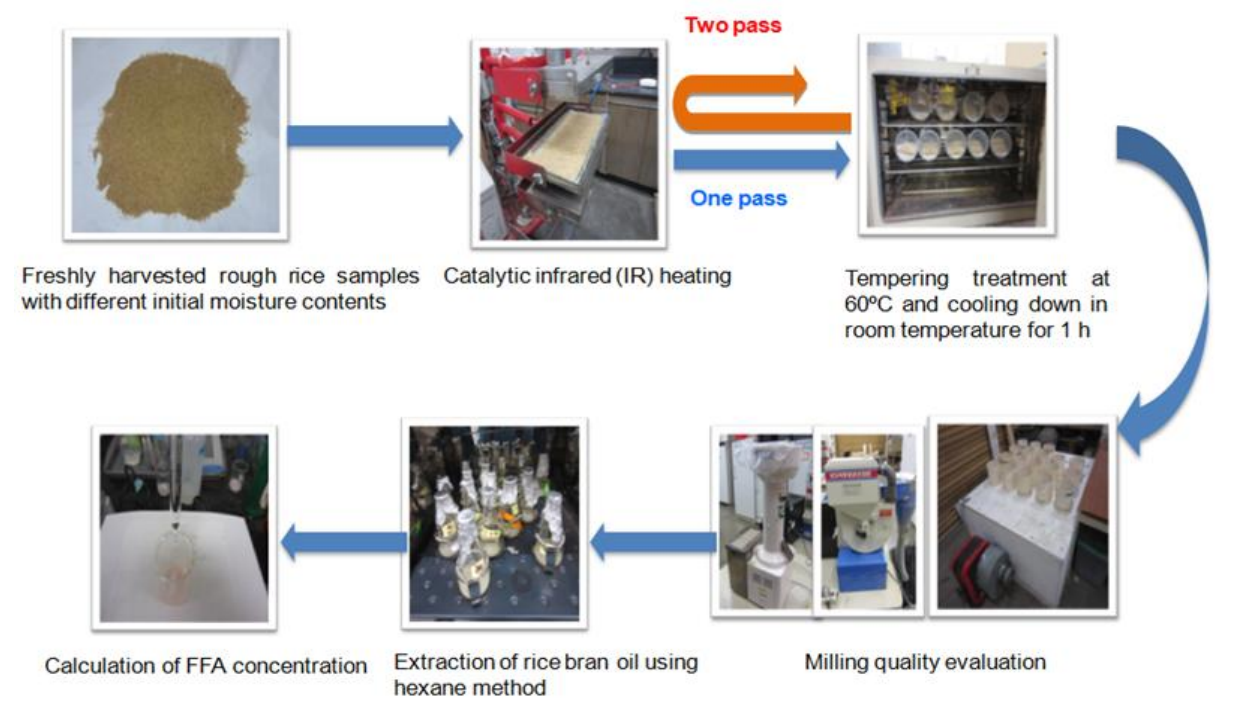

Figure 1. The procedures of IR heating, tempering treatment, and evaluation milling quality and FFA concentration. 


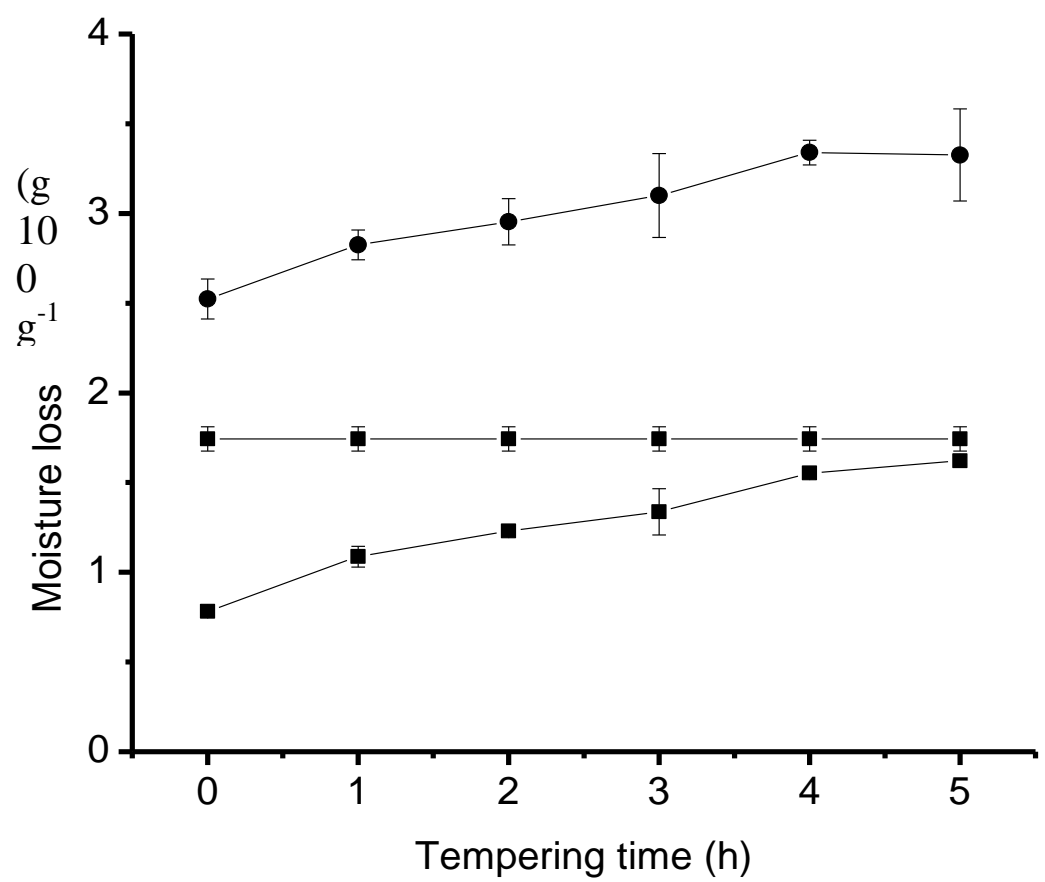

(a)

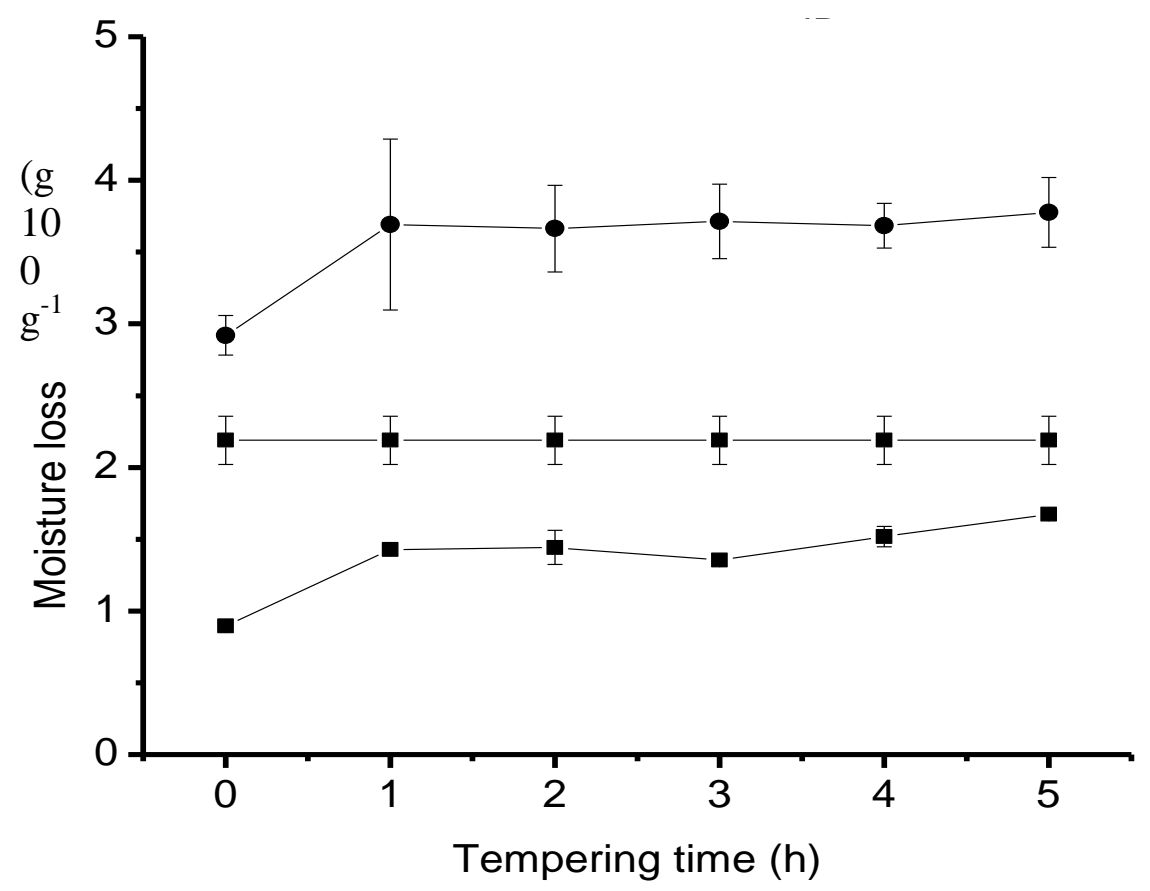

(b) 


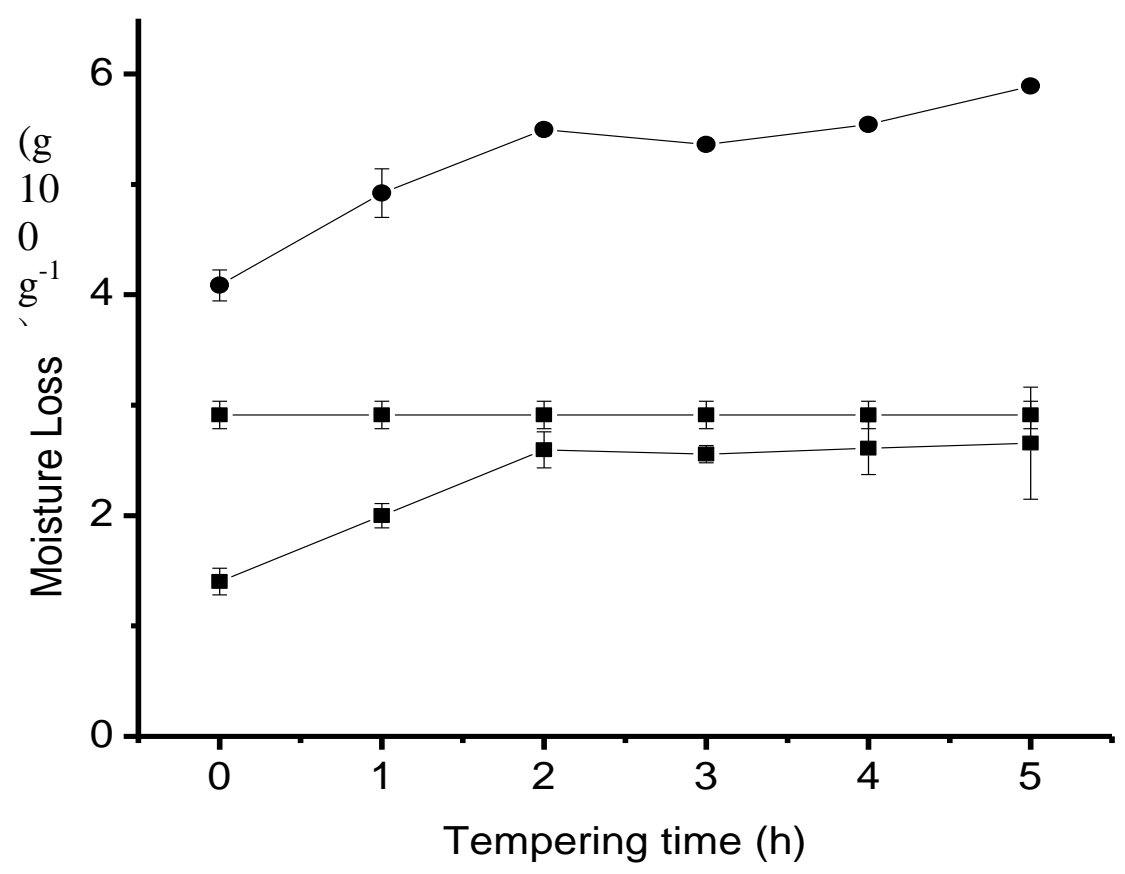

(c)

Figure 2. Moisture loss under infrared heating and tempering treatments for rough rice with IMC of (a) 20.06, (b) $25.45 \%$, and (c) $32.45 \mathrm{~g}$ moisture/100g dry solit IR Tempering,

- Total 


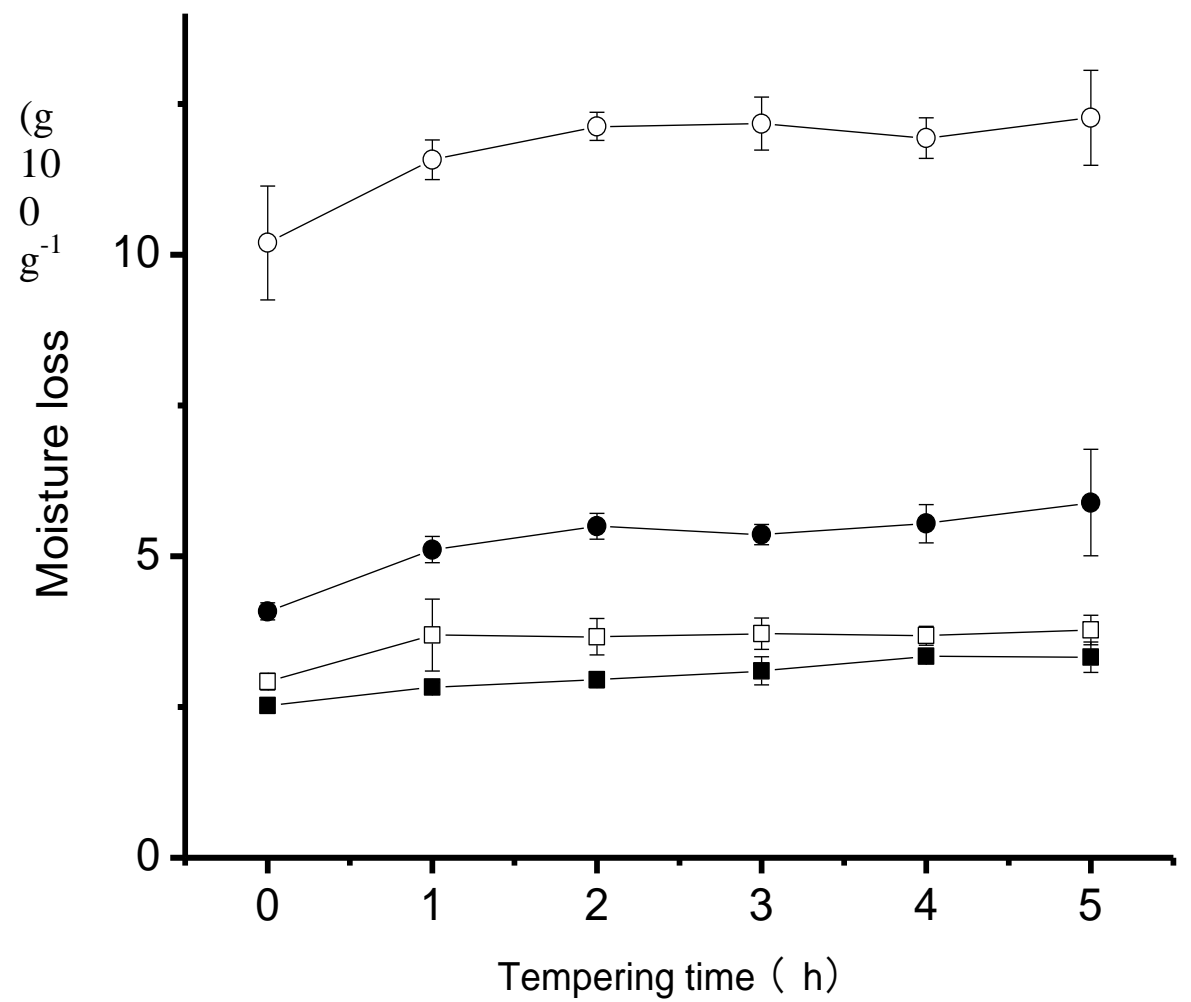

Figure 3. Moisture loss under infrared heating and tempering treatment for different durations at one- and two-pass drying for rough rice with IMC of 32.45\%. $20.06 \mathrm{~g}$ moisture/100g dry solid, $\square 25.53$ g moisture/100g dry solid, 32.50 g moisture/100g dry solid, $\bigcirc$ two passes. 


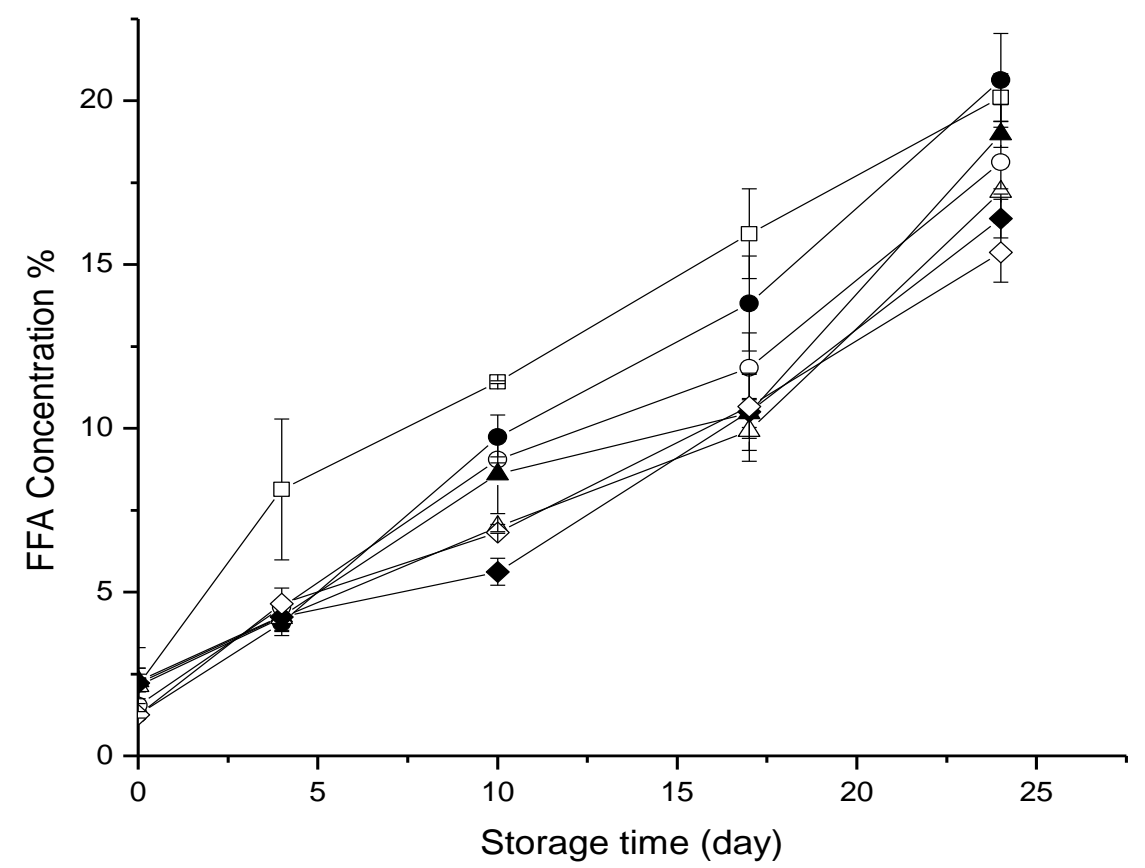

(a)

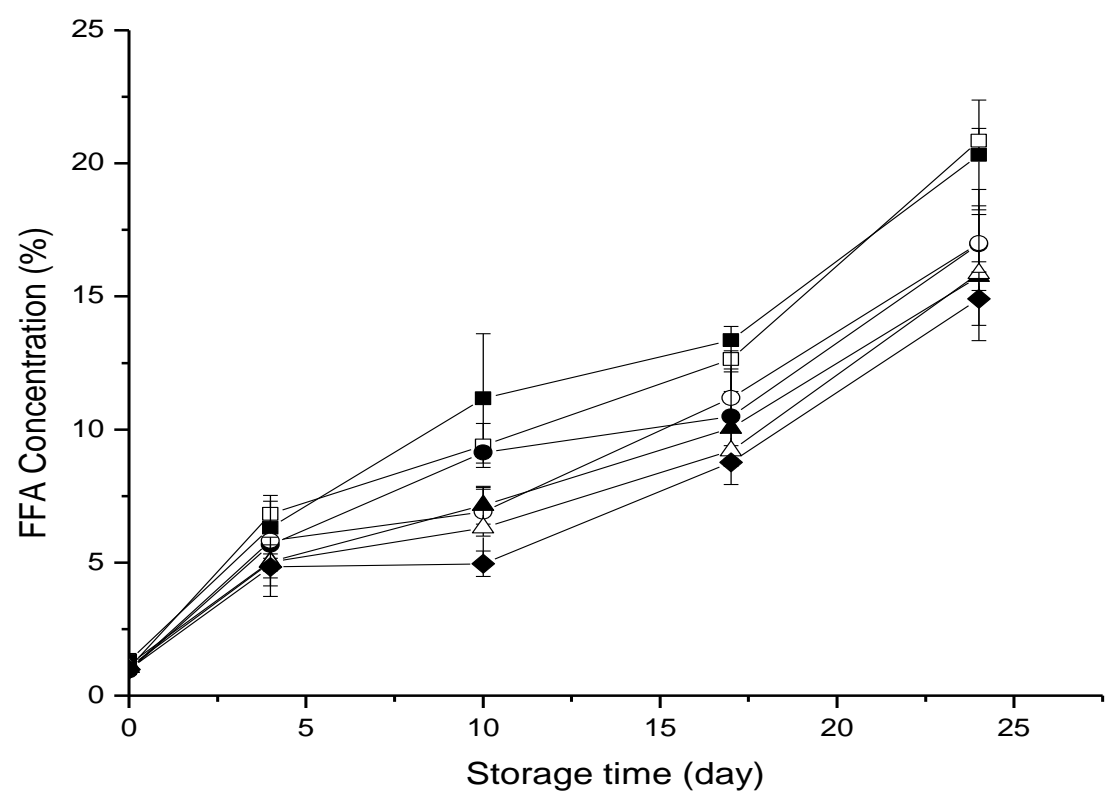

(b) 


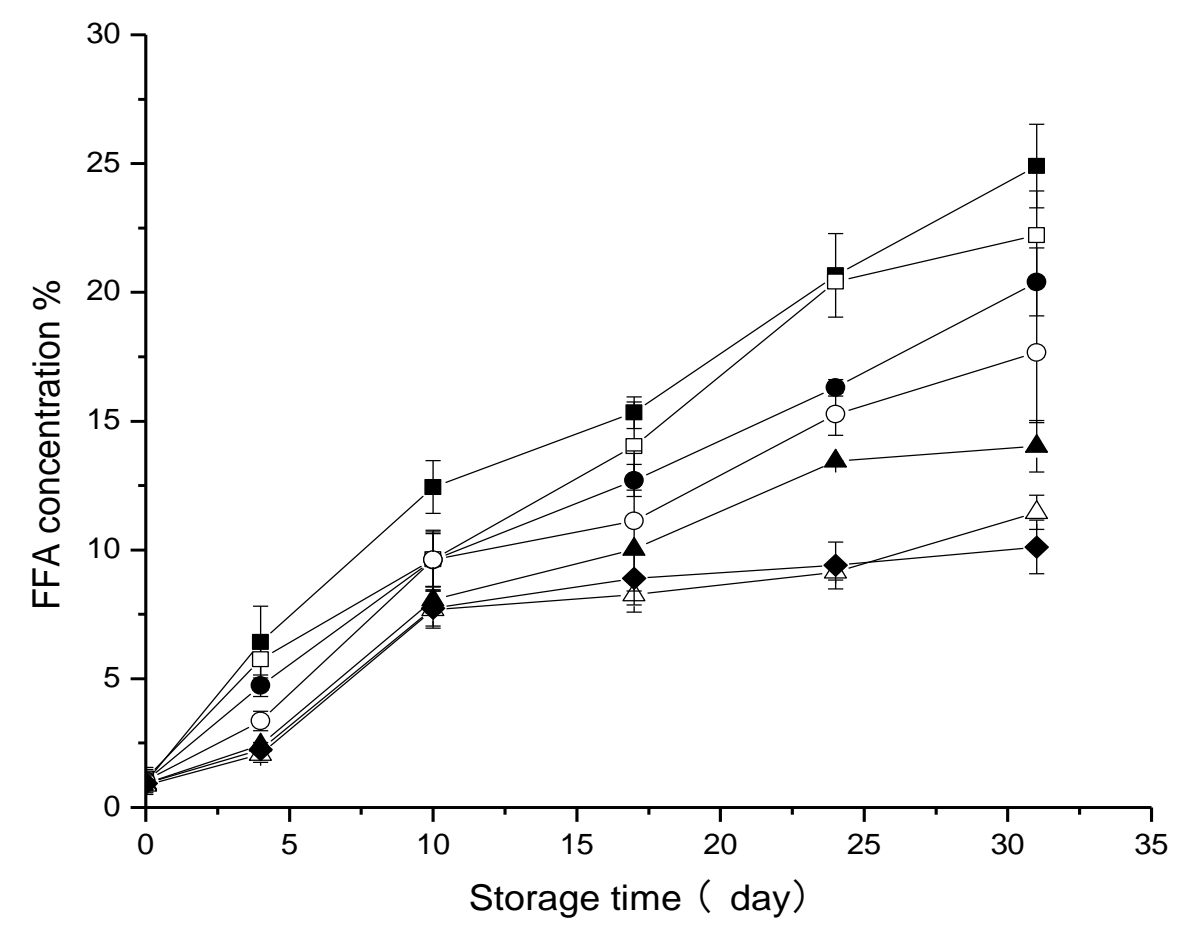

(c)

Fig 4. Total FFAs concentration (as oleic acid percentage in RBO) in treated rice bran of rice with different initial MCs, (a) 20.06, (b) 25.53 and (c) $32.50 \mathrm{~g}$ moisture/100g dry $\mathbf{D}$ lid. Co $\square$ rol, IR, $\quad$ Oempering -1h, $\Delta$ Tempering -2h, $\triangle$ Tempering -3 Tempering - 4h, Tempering - $5 \mathrm{~h}$. 


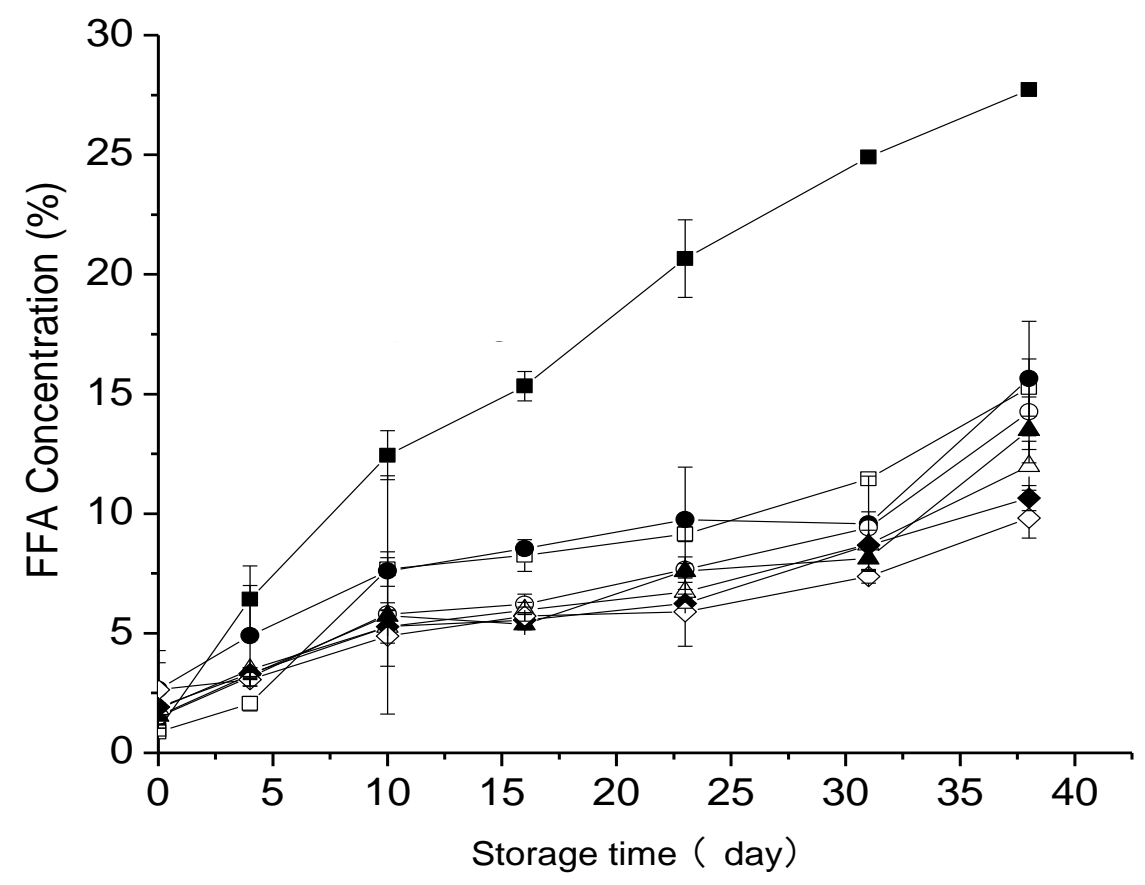

Fig 5. Total FFAs concentration (as oleic acid percentage in RBO) in two-pass treated rice bran of

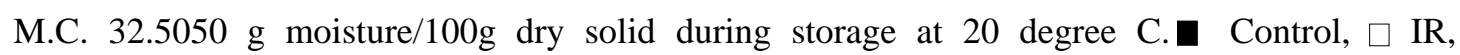
OTempering -1h, $\bigcirc$ Tempering -2h, $\Delta$ Tempering -3h, $\triangle$ Tempering - $4 \mathrm{~h}, \diamond$ Tempering - $5 \mathrm{~h}$. 